\title{
O Uso de Derivativos da Taxa de Câmbio e o Valor de Mercado das Empresas Brasileiras Listadas na Bovespa
}

The Use of Foreign Currency Derivatives and the Market Value of Brazilian Companies Listed at the Bovespa Stock Exchange

Danilo Guedine Serafini * E-mail: danilo.serafini@1dcommodities.com Louis Dreyfus Commodities S/A

São Paulo, SP, Brasil.

Hsia Hua Sheng E-mail: hsia.sheng@fgv.br Fundação Getúlio Vargas - FGV/EAESP

São Paulo, SP, Brasil.

Copyright (C) 2011 RAC. Todos os direitos, até mesmo de tradução, são reservados. É permitido citar parte de artigos sem autorização prévia, desde que seja identificada a fonte. 


\title{
Resumo
}

Este trabalho examina o impacto da utilização de derivativos de moedas no valor de mercado da firma, a partir de amostra das 48 empresas não-financeiras mais líquidas listadas na Bolsa de Valores de São Paulo, abrangendo o período de 1999 a 2007. Com base no trabalho de Allayannis e Weston (2001) e Rossi (2008), foram utilizadas três medidas do índice Q de Tobin como aproximação do valor da firma. Na regressão do modelo, utilizaram-se três métodos: pooled OLS, modelo de efeito fixo e modelo de efeito aleatório. Em seguida, é testada a causalidade reversa e a causalidade direta entre o uso de derivativos cambiais e o valor de mercado da firma. Os resultados empíricos encontrados demonstram que não há evidência de que o uso de derivativos de moedas está associado ao valor de mercado da firma. Nas regressões em pooled $O L S$, a hipótese de que o uso de derivativos cambiais aumenta o valor de mercado da firma foi aceita, porém estatisticamente não-significante. Já nas regressões de efeito fixo e efeito aleatório, a mesma hipótese não foi aceita e os resultados são estatisticamente significantes. Por fim, encontraram-se evidências de que tanto as empresas que iniciam o uso de derivativos de moeda quanto aquelas que deixaram de usar esses instrumentos, experimentam aumento de valor ao longo do tempo.

Palavras-chave: mercado de ações; derivativos, taxa de câmbio; valor da firma; risco cambial; gestão de risco.

\begin{abstract}
This paper examines the impact of using foreign currency derivatives on the market value of firms in a sample of the 48 most liquid non-financial companies listed at the "Bolsa de Valores de São Paulo" (São Paulo Stock Exchange) from 1999 to 2007. Based on the work of Allayanis and Weston (2001) and Rossi (2008), three measures of the Tobins' Q ratio were used as an approximation of a firm's value. The model is regressed using three methodologies: pooled OLS, fixed effect model and random walk model. Furthermore, the reverse causality and the direct causality between the use of foreign currency derivatives and the market value of firms are tested. The empirical results suggest that there is no clear evidence that the use of foreign currency derivatives is associated with a firm's market value. Concerning the pooled OLS regressions, the hypothesis that the use of foreign currency derivatives increases the market value of firms was accepted, but was statistically not significant. However, in the fixed effects and random walk regressions, we found negative but statistically significant results. Finally, evidence was found that the companies that start using foreign currency derivatives as well as those that stop using it, experience a higher market value.
\end{abstract}

Key words: stock market; derivatives; exchange rate; firm value; exchange rate fluctuation risk; risk management. 


\section{Introdução}

A taxa de câmbio é um dos fatores mais discutidos entre economistas e exerce grande influência no resultado das empresas, afetando também a economia do país. Intuitivamente diz-se que empresas exportadoras são afetadas positivamente pela depreciação cambial e que as importadoras são negativamente afetadas pela desvalorização do Real em face do dólar americano. Porém as empresas podem possuir filiais ou outros ativos no exterior, o que pode alterar seu coeficiente de sensibilidade ao dólar.

Com o crescimento da penetração de empresas brasileiras nos mercados externos, exige-se cada vez mais a prática de gerenciamento e controle de riscos de flutuação cambial. Nesse contexto, a obtenção de coeficientes de exposição cambial auxilia os gestores dessas empresas a tomarem decisões mais eficientes de hedge cambial e também de alocação de ativos e passivos fora do país. A sensibilidade das empresas ao câmbio é também objeto de interesse dos acionistas, já que alterações na taxa de câmbio afetam sua riqueza.

O avanço tecnológico, a integração dos mercados financeiros, a evolução dos modelos de precificação e a criação de produtos financeiros sofisticados podem explicar o rápido desenvolvimento do mercado de derivativos na última década. No entanto a literatura de finanças corporativas ainda não encontrou consenso no sentido de que a utilização de derivativos cambiais aumente o valor de mercado da firma.

Segundo Brando (2008), sob as premissas de mercado perfeito não há razões para uma firma fazer hedge. A empresa não gerará valor, ao se proteger das oscilações do mercado, com o uso de derivativos, se seus próprios acionistas podem posicionar-se nesses mesmos derivativos, caso desejem não se expor a estes riscos. No entanto o mundo não é perfeito; em determinadas situações, o uso de hedge pode criar valor para as empresas, como numa situação de assimetria de informação entre a empresa e os analistas externos, que só conseguiriam obter informações desta empresa, incorrendo em algum custo. Assim, a obtenção de financiamento externo para os novos investimentos seria mais custosa para a empresa do que o uso de fundos internos, ou seja, uma gestão de riscos neste caso serviria para garantir os recursos internos para os futuros projetos. Há também a simples decisão de financiar internamente o projeto por questões estratégicas, que teriam de ser reveladas, caso se busque financiamento no mercado financeiro ou de capitais. Por outro lado, quanto menos endividada uma empresa estiver, mais barata, marginalmente, uma emissão de dívida será. O hedge também poderia servir, então, para garantir estabilidade no fluxo de caixa e, consequentemente, aumentar a capacidade de endividamento da companhia.

Ainda, a volatilidade dos fluxos de caixa aumenta significativamente o risco de insolvência, podendo, em casos de variação extrema de preços, resultar na falência de alguns negócios. Um exemplo para estes casos são as sérias dificuldades que passaram algumas empresas em decorrência da variação cambial no final de 2008 e início de 2009. A volatilidade das variáveis macroeconômicas tem causado prejuízos significativos às empresas em todo o mundo e o isolamento dos riscos de variação cambial pode evitar tais prejuízos.

Allayannis e Weston (2001), num estudo realizado nos Estados Unidos que engloba 720 grandes empresas não-financeiras, encontraram resultados positivos e estatisticamente significativos para o impacto do uso de derivativos de moedas, no valor de mercado das empresas. Mais recentemente, Jin e Jorion (2006) realizaram um estudo sobre a atividade de hedge com 119 empresas americanas do setor de óleo e gás; concluíram que o uso de derivativos não afeta o valor de mercado das empresas.

Todavia Hagelin e Pramborg (2004), estudando uma amostra de 462 empresas suecas, concluíram que o sucesso da utilização de derivativos na redução da exposição cambial das empresas contribui positivamente para a riqueza dos acionistas. 
Contudo pouco foi publicado a respeito do uso de derivativos cambiais sobre o valor de mercado da firma, nos países emergentes. Em artigo recente, Rossi (2008) avaliou o impacto da utilização de derivativos no valor da firma com uma amostra de 175 empresas brasileiras nãofinanceiras, cotadas na Bovespa e encontrou resultados positivos e significativos em seu estudo.

À luz dessas pesquisas, o objetivo deste trabalho é examinar se o uso de derivativos de moedas tem influência no preço das ações das empresas não-financeiras mais líquidas, cotadas na Bovespa, baseando-se em Allayannis e Weston (2001). A nossa hipótese é que a utilização desses derivativos impacta positivamente o valor da firma, desde que controlemos os outros fatores, que a teoria sugere que devam influenciar seu valor.

O trabalho contribui no complemento de um estudo semelhante, publicado por Rossi (2008), ao focar nas questões da causalidade reversa e da causalidade direta da utilização de derivativos da taxa de câmbio no valor de mercado da firma. Para uma amostra de 48 empresas não-financeiras, listadas na Bolsa de Valores de São Paulo, abrangendo o período de julho 1999 a dezembro de 2007, no primeiro momento é examinado quanto as firmas usuárias de derivativos da taxa cambial têm maior valor do que as não usuárias. Posteriormente investigou-se quanto o prêmio do hedge pode ser explicado por outros fatores, que a teoria sugere que devam afetar o valor das empresas. Ainda, é pesquisada a relação de causalidade reversa entre o aumento do valor da firma e o uso de derivativos de moedas. Em seguida, testou-se a causalidade direta dessa relação, mediante um estudo de evento, seguindo Allayannis e Weston (2001).

O artigo está organizado da seguinte forma. Inicialmente descreveu-se a base de dados. Então a metodologia e os resultados são discutidos. A última seção conclui.

\section{Dados}

A amostra consiste em 48 ações negociadas na Bolsa de Valores de São Paulo. Foram incluídas todas as ações que compõem o índice IBrX-100 e também o índice Bovespa. Porém, neste estudo, foram excluídas as empresas do setor financeiro, pois elas são também market makers em derivativos da taxa de câmbio. Logo, suas motivações para usarem derivativos devem ser diferentes daquelas das empresas dos setores não-financeiros. Ainda, foram considerados apenas os papéis que estavam sendo negociados em julho de 1999 e permaneceram negociados até dezembro de 2007. Para todas as ações, a periodicidade das observações é mensal, considerando-se a cotação de fechamento do mês. As séries foram extraídas do banco de dados Economática. A amostra estende-se de julho de 1999, quando foi adotado o regime de câmbio flutuante e metas de inflação na política monetária brasileira, até dezembro de 2007.

O conjunto de 48 empresas é pequeno, se comparado com os utilizados em estudos americanos e até mesmo em outros estudos previamente realizados no mercado brasileiro. Porém é o que se encontra disponível para o Brasil, considerando aspectos como divulgação de informações e liquidez. Conforme Brito e Lima (2004), ser uma amostra viesada para grandes empresas brasileiras não é problema, pelo contrário, na medida em que são estes os negócios com escala para capturar todas as informações necessárias para a regressão dos modelos.

Conforme o mesmo critério usado por Rossi (2008), os dados sobre a utilização de derivativos de moeda foram coletados diretamente do balanço anual das empresas, localizados nas notas explicativas, sob o item instrumentos financeiros. Uma empresa foi considerada como usuária de derivativos, caso ela informe explicitamente o derivativo ou a política de proteção adotada. Porém, neste trabalho, apenas os instrumentos derivativos para a exposição cambial foram considerados. Os demais tipos de exposição para a qual são utilizados derivativos (juros e commodities, por exemplo) não foram considerados. Uma variável dummy é construída, assumindo o valor 1, caso a firma seja usuária de derivativos de moedas; caso contrário, esta assume o valor zero. 
Seguindo o critério de Tavares e Sheng (2007), também foram construídas carteiras sintéticas de ações, uma contendo somente ações de empresas exportadoras e outra composta pelas ações das empresas importadoras. Consideraram-se exportadoras as empresas que, em determinado ano, tiveram pelo menos $40 \%$ de sua receita total provenientes do exterior e as importadoras têm menos de $40 \%$ de sua receita total proveniente de vendas ao exterior. As informações que tiveram foram extraídas do resultado anual das empresas.

Construíram-se também portfólios para as empresas que, em determinado ano, utilizaram derivativos cambiais e para aquelas que não utilizaram derivativos. Ainda, foram separadas as empresas que possuem vendas externas daquelas que têm $100 \%$ de suas operações no mercado doméstico.

Seguindo Rossi (2008) e diferentemente de Allayannis e Weston (2001), estimaram-se os modelos com todas as empresas da amostra e não somente confinadas às empresas exportadoras, devido ao alto grau de exposição ao câmbio das empresas brasileiras, por outros fatores que não somente suas vendas externas.

Foi utilizado o índice $\mathrm{Q}$ de Tobin como proxy do valor de mercado das empresas, seguindo o modelo sugerido por Allayannis e Weston (2001) e também Jin e Jorion (2006). O índice Q de Tobin, proposto originalmente por Tobin e Brainard (1968) e Tobin (1969), é definido como a relação do valor de mercado da firma e o valor de reposição dos seus ativos físicos ${ }^{(1)}$. Assim, conforme observou Reinhart (1977), ele representa a razão entre dois valores atribuídos ao mesmo conjunto de ativos.

$\mathrm{Na}$ construção do valor de mercado e do custo de reposição dos ativos das empresas, a metodologia adotada se aproxima daquela utilizada por Lewellen e Badrinath (1997). Foi calculado o custo de reposição dos ativos como a soma do custo de reposição dos ativos fixos mais inventários. No cálculo do valor de mercado das equidades e dívidas das empresas, tomou-se por base um processo desenvolvido por Lewellen e Badrinath (1997) e Perfect e Wiles $(1994)^{(2)}$. O valor de mercado das empresas foi extraído diretamente do banco de dados Economática, bem como o valor contábil de suas dívidas. Conforme sugerido por Lang e Stulz (1994), foi estimado o valor de mercado das ações, usando o valor terminal do fim do ano.

A fim de investigar a sensitividade dos resultados ao índice Q de Tobin, construíram-se três medidas alternativas, assim como fizeram Allayannis e Weston (2001) e, posteriormente, Rossi (2008). Para as empresas da amostra, foram obtidos dados a respeito do uso de derivativos mediante as informações contidas nas notas explicativas dos relatórios anuais de cada ano. A proxy uso de derivativos cambiais na amostra inclui: contratos a termo, opções de moedas estrangeiras, swaps e futuros de moedas. As empresas que reportaram o uso de derivativos de moeda, mas não relataram o nível do uso, também foram consideradas usuárias de derivativos de moedas.

\section{Variáveis de controle}

Para afirmar que o uso de derivativos de moedas aumenta o valor de mercado das empresas, precisa-se excluir os efeitos das outras variáveis que possam ter impacto no valor $\mathrm{Q}$ da firma. Estão descritas abaixo as variáveis de controle utilizadas nos testes e as razões teóricas que nos levaram a utilizá-las. Foram seguidos Allayannis e Weston (2001) na escolha das variáveis de controle, porém foram excluídos do modelo os controles rating de crédito, efeitos da indústria e diversificação industrial. Não se encontram informações disponíveis suficientes para o controle rating de crédito. Quanto aos controles efeitos da indústria e diversificação industrial, optou-se por não utilizá-los, uma vez que a amostra deste estudo é muito homogênea e pouquíssimas empresas pertenciam a mais de um segmento industrial. Todavia acrescentaram-se no modelo os controles: liquidez, vendas externas e exportadores Vs importadores. 
Tabela 1

Variáveis de Controle e Descrições

\begin{tabular}{ll}
\hline \multicolumn{1}{c}{ Variável de controle } & \multicolumn{1}{c}{ Descrição } \\
\hline$\underline{\text { Tamanho }}$ & $\begin{array}{l}\text { Não há clara evidência de que o tamanho das empresas as leve a maiores } \\
\text { lucros contábeis. No entanto, quanto maior a empresa, mais derivativos } \\
\text { ela usa; por exemplo, devido à existência de altos custos fixos iniciais de } \\
\text { Proxy: Logaritmo do Ativo Total } \\
\text { controle tamanho. }\end{array}$
\end{tabular}

$\underline{\text { Acesso aos mercados financeiros }}$

Se os usuários de hedge abandonam projetos, por não obterem Proxy: Dummy Dividendos: 1 se pagou naquele ano; 0 C.C. financiamento necessário, seus índices Qs devem permanecer elevados, pois eles apenas retêm projetos cujo valor presente líquido seja positivo. A proxy utilizada para captar a habilidade das empresas em acessar os mercados financeiros é a dummy dividendos, que se iguala a um, se a firma pagou dividendos no ano corrente. Se a empresa pagou dividendos, é mais improvável que ela tenha sofrido restrições de capital e, portanto, deve ter o índice $\mathrm{Q}$ reduzido.

\author{
Alavancagem \\ Proxy: Dívida de longo \\ prazo/Patrimônio Líquido \\ Lucratividade \\ Proxy: Receita Líquida / Ativo \\ Total
}

Oportunidades de investimentos Proxy: CAPEX / Vendas Totais

$\underline{\text { Liquidez }}$

Proxy: Ativo Circulante / Passivo Circulante

\section{Diversificação Geográfica}

Proxy: Vendas Externas / Vendas Totais
A estrutura de capital da empresa também deve estar relacionada ao seu valor. Para controlar diferenças na estrutura de capital, usou-se uma variável de alavancagem definida como dívida de longo prazo, dividida pelas equidades dos acionistas.

Uma empresa lucrativa provavelmente é negociada com um prêmio, relativamente a uma empresa menos lucrativa. Então, se as firmas usuárias de derivativos cambiais são mais lucrativas, elas terão um índice Q maior. Para controlar a lucratividade, usou-se o retorno dos ativos, definido como o índice das receitas líquidas sobre o total de ativos.

Myers (1977) e Smith e Watts (1992) argumentaram que as empresas também dependem de oportunidades futuras de investimento. Como as firmas usuárias de derivativos têm provavelmente mais oportunidades de investimento, este controle é importante. Semelhantemente aos estudos de Yermack (1996) e Servaes (1996) e Allayannis e Weston (2001), foi utilizado o índice de gastos de capital sobre vendas, como proxy de oportunidade de investimento.

Da mesma forma que se controlou o acesso aos mercados financeiros e consistente com o argumento do free cash flow de Jensen (1986), se os usuários de derivativos abandonam projetos por não obterem financiamento necessário, seus índices Qs devem permanecer elevados, pois eles apenas retêm projetos cujo valor presente líquido seja positivo. Logo, empresas mais líquidas teriam o valor Q mais baixo. Seguindo Pramborg (2004) e posteriormente Rossi (2008), utilizou-se como proxy da liquidez da firma, a variável de liquidez corrente, que é a razão entre o ativo e o passivo circulante da firma.

Várias teorias sugerem que a diversificação geográfica (multinacionalização) aumenta o valor da firma. Por exemplo, a teoria da internacionalização diz que investimentos externos diretos ocorrem, quando uma empresa pode aumentar seu valor, internalizando mercados para alguns de seus ativos intangíveis, como gratidão do consumidor. Outras teorias sugerem que isso é uma consequência do problema de agência, igualmente a diversificação industrial. Morck e Yeung (1991) e Bodnar, Tang e Weintrop (1999), entre outros, encontraram que a multinacionalização é positivamente relacionada ao valor da empresa. Foi utilizado o índice de vendas externas sobre vendas totais como medida contínua de multinacionalidade nos testes. 


\section{Tabela 1 (continuação)}

\begin{tabular}{|c|c|}
\hline Variável de controle & Descrição \\
\hline $\begin{array}{l}\text { Exportadora ou Importadora } \\
\text { Proxy: Dummy: } 1 \text { caso a empresa } \\
\text { tenha vendas externas }>=40 \% \text { do } \\
\text { total das vendas; } 0 \text { C.C. }\end{array}$ & $\begin{array}{l}\text { Se as empresas exportadoras concentram indústrias com alto valor Q, } \\
\text { então essas empresas poderão ter maior valor, não porque usam } \\
\text { derivativos, mas porque têm grande parte de suas receitas provenientes do } \\
\text { exterior. Logo, foi utilizada uma variável dummy, que assume valor } 1 \text {, se } \\
\text { a firma possui mais de } 40 \% \text { de seu faturamento total proveniente de } \\
\text { exportações e valor } 0 \text {, caso contrário. }\end{array}$ \\
\hline $\begin{array}{l}\text { Efeitos do tempo } \\
\text { Proxy: Dummies para cada ano no } \\
\text { período de } 1999 \text { a } 2007 .\end{array}$ & $\begin{array}{l}\text { Controlamos também o efeito do tempo, usando dummies anuais em todas } \\
\text { as regressões. }\end{array}$ \\
\hline $\begin{array}{l}\text { Vendas externas } \\
\text { Proxy: Dummy: } 1 \text { caso a empresa } \\
\text { exportou num determinado ano; } 0 \\
\text { C.C. }\end{array}$ & $\begin{array}{l}\text { Finalmente, da mesma forma que se controlaram indústrias exportadoras e } \\
\text { importadoras, também foram controladas as empresas que possuem } \\
\text { vendas externas daquelas que atuam somente no mercado doméstico. } \\
\text { Utilizou-se uma variável dummy, que assume valor } 1 \text {, caso a empresa } \\
\text { tenha receitas provenientes do exterior; e valor } 0 \text {, caso contrário. }\end{array}$ \\
\hline
\end{tabular}

\section{Metodologia e Resultados Empíricos}

Além dos resultados empíricos, esta seção apresenta a base teórica e as inter-relações das variáveis utilizadas no modelo. Enfatizamos que não pretendemos esgotar nem formalizar nenhuma teoria, mas apenas apresentar a sistemática do funcionamento dos modelos adotados neste trabalho.

Foram utilizadas três medidas do índice Q, seguindo outros trabalhos, a exemplo de Famá e Barros (2000), que estudaram as principais implicações teóricas e empíricas deste índice, com ênfase especial em suas aplicações em finanças.

Na primeira medida do Q de Tobin, optou-se por uma metodologia semelhante à Pramborg (2004), Allayannis, Lel e Miller (2007).

$$
Q 1=\frac{A T-V C E+V M E}{A T}
$$

Onde AT representa o valor contábil dos ativos, VCE é o valor contábil do patrimônio líquido e VME indica o valor de mercado do patrimônio líquido.

Para permitir comparações com outros trabalhos e testar a precisão do modelo num exercício de robustez, foram propostas ainda duas metodologias alternativas para o cálculo do Q de Tobin, seguindo Rossi (2008). Chung e Pruitt (1994) definem essa medida como:

$$
Q 2=\frac{V M A+V C P C-V C A C+V C E+V C D L P}{A T}
$$

Onde VMA é o valor de mercado da firma. VCPC é o valor contábil do passivo circulante da firma, VCAC representa o valor contábil do ativo circulante, VCE é o valor contábil dos estoques e VCDLP é representado pelo valor contábil da dívida de longo prazo. AT representa o ativo total da firma.

Outra medida alternativa foi sugerida por Shin e Stulz (2000), que utilizaram a seguinte medida para o Q de Tobin: 


$$
Q 3=\frac{V M A+V C D}{A T}
$$

Onde novamente VMA representa o valor de mercado da firma e VCD é o valor contábil das dívidas. O AT é o valor total dos ativos.

Para capturar a relação entre o uso de derivativos cambiais e o valor de mercado da firma, precisa-se controlar as variáveis que possam ter impacto no índice $\mathrm{Q}$, conforme se menciona na seção anterior. Controlaram-se especificamente as variáveis listadas na tabela 1.

Primeiramente testou-se a hipótese de que o uso de derivativos de moedas aumenta o valor de mercados da firma, por meio de um teste uni variado ao longo do tempo. Analisaram-se as variáveis separadas em grupos de empresas que utilizam derivativos de moedas e empresas que não utilizam tais derivativos.

Tabela 2

\section{Perfil da Amostra quanto ao Uso de Derivativos de Moedas ao Longo do Tempo}

\begin{tabular}{|c|c|c|c|c|c|c|c|c|c|}
\hline \multicolumn{10}{|c|}{ Perfil do uso de derivativos de moedas ao longo do tempo } \\
\hline & 1999 & 2000 & 2001 & 2002 & 2003 & 2004 & 2005 & 2006 & 2007 \\
\hline \multicolumn{10}{|c|}{ Total de empresas da amostra } \\
\hline & 48 & 48 & 48 & 48 & 48 & 48 & 48 & 48 & 48 \\
\hline \multicolumn{10}{|c|}{ Número de empresas que usam derivativos de moedas } \\
\hline & 28 & 32 & 37 & 38 & 40 & 41 & 41 & 41 & 37 \\
\hline \multicolumn{10}{|c|}{ Percentual da amostra } \\
\hline & $58 \%$ & $67 \%$ & $77 \%$ & $79 \%$ & $83 \%$ & $85 \%$ & $85 \%$ & $85 \%$ & $77 \%$ \\
\hline \multicolumn{10}{|c|}{ Número de empresas que possuem vendas externas } \\
\hline $\begin{array}{l}\text { Usa derivativos } \\
\text { cambiais }\end{array}$ & 19 & 20 & 23 & 25 & 25 & 26 & 26 & 26 & 24 \\
\hline $\begin{array}{l}\text { Percentual da } \\
\text { amostra }\end{array}$ & $73 \%$ & $77 \%$ & $88 \%$ & $93 \%$ & $93 \%$ & $93 \%$ & $93 \%$ & $93 \%$ & $86 \%$ \\
\hline $\begin{array}{l}\text { Não usa derivativos } \\
\text { cambiais }\end{array}$ & 7 & 6 & 3 & 2 & 2 & 2 & 2 & 2 & 4 \\
\hline $\begin{array}{l}\text { Percentual da } \\
\text { amostra }\end{array}$ & $27 \%$ & $23 \%$ & $12 \%$ & $7 \%$ & $7 \%$ & $7 \%$ & $7 \%$ & $7 \%$ & $14 \%$ \\
\hline \multicolumn{10}{|c|}{ Número de empresas que pagaram dividendos } \\
\hline $\begin{array}{l}\text { Usa derivativos } \\
\text { cambiais }\end{array}$ & 16 & 19 & 25 & 30 & 33 & 37 & 37 & 38 & 36 \\
\hline $\begin{array}{l}\text { Percentual da } \\
\text { amostra }\end{array}$ & $53 \%$ & $59 \%$ & $76 \%$ & $81 \%$ & $83 \%$ & $88 \%$ & $86 \%$ & $86 \%$ & $78 \%$ \\
\hline $\begin{array}{l}\text { Não usa derivativos } \\
\text { cambiais }\end{array}$ & 14 & 13 & 8 & 7 & 7 & 5 & 6 & 6 & 10 \\
\hline $\begin{array}{l}\text { Percentual da } \\
\text { amostra }\end{array}$ & $47 \%$ & $41 \%$ & $24 \%$ & $19 \%$ & $18 \%$ & $12 \%$ & $14 \%$ & $14 \%$ & $22 \%$ \\
\hline \multicolumn{10}{|c|}{ Tamanho - Média (em R\$ milhares) } \\
\hline $\begin{array}{l}\text { Usa derivativos } \\
\text { cambiais }\end{array}$ & $7,299.31$ & $8,277.51$ & $9,747.25$ & $11,432.25$ & $13,005.81$ & $14,283.48$ & $16,015.88$ & $19,506.58$ & $23,518.03$ \\
\hline $\begin{array}{l}\text { Não usa derivativos } \\
\text { cambiais }\end{array}$ & $10,072.77$ & $12,354.23$ & $15,848.89$ & $19,166.93$ & $20,827.31$ & $23,571.61$ & $23,902.46$ & $24,362.04$ & $17,994.40$ \\
\hline
\end{tabular}




\section{Tabela 2 (continuação)}

\begin{tabular}{|c|c|c|c|c|c|c|c|c|c|}
\hline \multicolumn{10}{|c|}{ Perfil do uso de derivativos de moedas ao longo do tempo } \\
\hline & 1999 & 2000 & 2001 & 2002 & 2003 & 2004 & 2005 & 2006 & 2007 \\
\hline \multicolumn{10}{|c|}{ Alavancagem - Média } \\
\hline $\begin{array}{l}\text { Usa derivativos } \\
\text { cambiais }\end{array}$ & 0.80 & 1.08 & -0.09 & 1.18 & 0.92 & 0.76 & 0.79 & 0.88 & 0.86 \\
\hline $\begin{array}{l}\text { Não usa derivativos } \\
\text { cambiais }\end{array}$ & 0.51 & 0.47 & 0.51 & 0.75 & 0.57 & 0.62 & 0.51 & 0.31 & 0.41 \\
\hline \multicolumn{10}{|c|}{ Rentabilidade - Média } \\
\hline $\begin{array}{l}\text { Usa derivativos } \\
\text { cambiais }\end{array}$ & 0.57 & 0.60 & 0.63 & 0.62 & 0.71 & 0.78 & 0.76 & 0.71 & 0.75 \\
\hline $\begin{array}{l}\text { Não usa derivativos } \\
\text { cambiais }\end{array}$ & 0.38 & 0.46 & 0.43 & 0.41 & 0.46 & 0.46 & 0.48 & 0.46 & 0.57 \\
\hline \multicolumn{10}{|c|}{ Oportunidade de Investimento - Média } \\
\hline $\begin{array}{l}\text { Usa derivativos } \\
\text { cambiais }\end{array}$ & 130.13 & 139.91 & 182.87 & 100.62 & 86.75 & 94.41 & 95.52 & 122.23 & 121.77 \\
\hline $\begin{array}{l}\text { Não usa derivativos } \\
\text { cambiais }\end{array}$ & 126.63 & 122.68 & 96.50 & 104.65 & 123.30 & 88.09 & 98.47 & 113.73 & 106.67 \\
\hline \multicolumn{10}{|c|}{ Liquidez - Média } \\
\hline $\begin{array}{l}\text { Usa derivativos } \\
\text { cambiais }\end{array}$ & 1.25 & 1.37 & 1.24 & 1.20 & 1.22 & 1.34 & 1.59 & 1.70 & 1.62 \\
\hline $\begin{array}{l}\text { Não usa derivativos } \\
\text { cambiais }\end{array}$ & 1.14 & 1.40 & 1.34 & 1.22 & 1.41 & 1.75 & 1.67 & 1.73 & 1.49 \\
\hline \multicolumn{10}{|c|}{ Diversifcação Geográfica - Média } \\
\hline $\begin{array}{l}\text { Usa derivativos } \\
\text { cambiais }\end{array}$ & 0.22 & 0.19 & 0.20 & 0.24 & 0.22 & 0.23 & 0.22 & 0.23 & 0.26 \\
\hline $\begin{array}{l}\text { Não usa derivativos } \\
\text { cambiais }\end{array}$ & 0.08 & 0.11 & 0.07 & 0.05 & 0.06 & 0.13 & 0.12 & 0.11 & 0.11 \\
\hline \multicolumn{10}{|c|}{ Q de Tobin (Q1) - Média } \\
\hline $\begin{array}{l}\text { Usa derivativos } \\
\text { cambiais }\end{array}$ & 1.29 & 1.18 & 1.13 & 1.18 & 1.53 & 1.57 & 1.55 & 1.78 & 2.11 \\
\hline $\begin{array}{l}\text { Não usa derivativos } \\
\text { cambiais }\end{array}$ & 1.11 & 0.99 & 0.97 & 1.00 & 1.21 & 1.37 & 1.45 & 1.59 & 1.74 \\
\hline \multicolumn{10}{|c|}{ Q de Tobin (Q2) - Média } \\
\hline $\begin{array}{l}\text { Usa derivativos } \\
\text { cambiais }\end{array}$ & 0.85 & 0.72 & 0.68 & 0.71 & 1.03 & 1.06 & 1.03 & 1.28 & 1.62 \\
\hline $\begin{array}{l}\text { Não usa derivativos } \\
\text { cambiais }\end{array}$ & 0.79 & 0.64 & 0.61 & 0.61 & 0.78 & 0.89 & 0.96 & 1.10 & 1.27 \\
\hline \multicolumn{10}{|c|}{ Q de Tobin (Q3) - Média } \\
\hline $\begin{array}{l}\text { Usa derivativos } \\
\text { cambiais }\end{array}$ & 1.03 & 0.93 & 0.86 & 0.92 & 1.25 & 1.26 & 1.24 & 1.50 & 1.81 \\
\hline $\begin{array}{l}\text { Não usa derivativos } \\
\text { cambiais }\end{array}$ & 0.88 & 0.76 & 0.70 & 0.71 & 0.91 & 1.05 & 1.13 & 1.28 & 1.43 \\
\hline
\end{tabular}

Nota. Resumo do uso de derivativos de moedas ao longo do tempo. A empresa é considerada usuária de derivativos de moedas em certo ano, se ela reportou o uso de forwards, futuros, opções, ou swaps cambiais naquele ano.

Nota-se que ao longo do tempo mais empresas tendem a utilizar derivativos de moedas, salvo no ano de 2007, quando ocorreu um declínio nesse número, voltando aos padrões de 2001. Quando 
analisada a amostra de empresas que possuem vendas externas, nota-se um número altíssimo de empresas que fazem derivativos cambiais. Em 1999, $73 \%$ dessas empresas já adotavam essa prática, chegando a $93 \%$ no ano de 2006.

Os números observados na Tabela 2 sugerem que as empresas brasileiras enxergam os ativos externos como complemento do uso de derivativos cambiais. Observa-se que os usuários de derivativos têm uma razão de vendas externas sobre vendas totais muito maior do que os não usuários, resultado esse consistente com o observado por Rossi (2008).

É notado que as empresas que usam derivativos de moedas são muito mais propensas à distribuição de dividendos do que aquelas não usuárias. Esse resultado sugere que as firmas utilizam derivativos como meio de sinalizar aos investidores que ela se esforça para minimizar a flutuação de seu fluxo de caixa. Ainda, os resultados encontrados sugerem que as empresas da amostra, usuárias de derivativos de moedas, são em média menores do que as não usuárias.

Os resultados com respeito à hipótese de que as empresas usam derivativos para evitar financial distress são consistentes. Observa-se que as empresas que usam derivativos de moedas possuem índice médio de alavancagem muito superior ao daquelas que não usam derivativos.

Observa-se que as empresas da amostra que utilizam derivativos de moedas são em média $22 \%$ mais rentáveis que as empresas que não os utilizam. Esse resultado sinaliza que o uso de derivativos reduz a volatilidade do fluxo de caixa das empresas, proporcionando-lhes melhor gestão de seus ativos.

Finalmente, observa-se na Tabela 2 que a hipótese de que empresas que utilizam derivativos de moedas possuem valor de mercado superior ao daquelas que não os utilizam é consistente. Nota-se que, ao longo do tempo, as empresas da amostra que fizeram derivativos cambiais possuem um índice $\mathrm{Q}$ de Tobin $21 \%$ superior ao daquelas que não fizeram.

Verifica-se que o comportamento do dólar, ao longo do ano, exerce o pass-through e também influencia o valor de mercado das empresas. Conforme observaram Allayannis e Weston (2001), se as empresas com vendas externas estão normalmente compradas em moeda estrangeira, seu valor de mercado aumentará, se o Real se depreciar; e diminuirá, se o Real se apreciar. No entanto a diferença relativa de valor entre firmas que usam derivativos cambiais e aquelas que não usam irá flutuar em razão do movimento do dólar. Portanto, foi também testada essa hipótese, separando em anos nos quais o Real se apreciou e em anos em que o Real se depreciou (ver resultados na Tabela 3).

Observa-se que, surpreendentemente, as empresas que exportam e usam derivativos de moedas possuem o índice Q1 médio aproximadamente 30\% menor que aquelas que exportam, mas não usam derivativos. Porém, quando observada a mediana, percebe-se que a diferença do índice Q, observada acima, cai para 7\%. Logo, uma explicação para esse resultado pode ser o pequeno número da amostra de empresas que exportam e não fazem derivativos de moedas. Esse conjunto além de pequeno apresenta um desvio padrão muito elevado, sugerindo que poucas empresas contribuíram para elevar o Q médio.

Separando-se os períodos em que o real se apreciou em relação ao dólar e vice-versa, constatase que, no primeiro caso, a diferença entre o $\mathrm{Q}$ médio das empresas que usam derivativos e daquelas que não usam é muito mais significativa (mais que o dobro) do que no segundo. Esse resultado é inconsistente com os números observados por Allayannis e Weston (2001). 
Tabela 3

Resultado dos Testes Univariados. Perfil da Amostra quanto ao Uso de Derivativos de Moedas

\begin{tabular}{|c|c|c|c|c|c|c|}
\hline \multicolumn{7}{|c|}{ Comparação dos Qs: Usam derivados de moedas Vs não usam derivados de moedas } \\
\hline & \multicolumn{2}{|c|}{ Vendas externas $>0$} & \multicolumn{2}{|c|}{ Vendas externas $=0$} & \multirow[b]{2}{*}{ Diferença } & \multirow[b]{2}{*}{ Diferença } \\
\hline & $\begin{array}{c}\text { Usam } \\
\text { derivativos } \\
\text { cambiais }\end{array}$ & $\begin{array}{c}\text { Não usam } \\
\text { derivativos } \\
\text { cambiai }\end{array}$ & $\begin{array}{c}\text { Usam } \\
\text { derivativos } \\
\text { cambiais }\end{array}$ & $\begin{array}{c}\text { Não usam } \\
\text { derivativos } \\
\text { cambiais }\end{array}$ & & \\
\hline Painel A: Diferenças das médias & (1) & (2) & (3) & (4) & & \\
\hline Todos os anos & Q1 & Q1 & Q1 & Q1 & (1) $-(2)$ & (3) - (4) \\
\hline Média & 1,36 & 1,99 & 1,49 & $\mathbf{0 , 9 0}$ & $-0,63$ & $\mathbf{0 , 5 9}$ \\
\hline Desv. Pad. & 0,58 & 1,15 & 0,79 & $\mathbf{0 , 5 2}$ & & \\
\hline $\mathbf{N}$ & 198 & 30 & 122 & 67 & & \\
\hline \multicolumn{7}{|l|}{ Real apreciou-se } \\
\hline Média & 1,50 & 2,28 & 1,62 & 0,99 & $-0,78$ & $\mathbf{0 , 6 3}$ \\
\hline Desv. Pad. & $\mathbf{0 , 5 8}$ & 1,29 & 0,91 & 0,63 & & \\
\hline $\mathbf{N}$ & 135 & 19 & 83 & 41 & & \\
\hline \multicolumn{7}{|l|}{ Real depreciou-se } \\
\hline Média & $\mathbf{1 , 0 7}$ & 1,40 & 1,24 & 0,72 & $-0,33$ & $\mathbf{0 , 5 2}$ \\
\hline Desv. Pad. & 0,48 & 0,61 & $\mathbf{0 , 3 2}$ & 0,16 & & \\
\hline $\mathbf{N}$ & 63 & 11 & 39 & 26 & & \\
\hline & \multicolumn{2}{|c|}{ Vendas externas $>0$} & \multicolumn{2}{|c|}{ Vendas externas $=0$} & & \\
\hline & $\begin{array}{c}\text { Usam } \\
\text { derivativos } \\
\text { cambiais }\end{array}$ & $\begin{array}{c}\text { Não usam } \\
\text { derivativos } \\
\text { cambiais }\end{array}$ & $\begin{array}{c}\text { Usam } \\
\text { derivativos } \\
\text { cambiais }\end{array}$ & $\begin{array}{c}\text { Não usam } \\
\text { derivativos } \\
\text { cambiais }\end{array}$ & Diferença & Diferença \\
\hline
\end{tabular}

Painel A: Diferenças das médianas

\begin{tabular}{lcccccc} 
& Q1 & Q1 & Q1 & Q1 & & \\
Todos os anos & 1,31 & 1,39 & 1,29 & 0,77 & $\mathbf{- 0 , 0 9}$ & $\mathbf{0 , 5 2}$ \\
Real apreciou-se & 1,42 & 1,80 & 1,36 & 0,85 & $\mathbf{- 0 , 3 8}$ & $\mathbf{0 , 5 1}$ \\
Real depreciou-se & 0,96 & 0,93 & 1,12 & 0,72 & 0,03 & 0,40 \\
\hline
\end{tabular}

Já ao comparar o índice Q para as empresas que não exportam, o resultado é o inverso, ou seja, as empresas que usam derivativos cambiais possuem o Q1 mais alto do que as empresas que não usam esses derivativos. Esse resultado é consistente ao encontrado por Allayannis e Weston (2001). Quanto aos períodos de apreciação e depreciação do real em face do dólar, verifica-se que no primeiro caso a diferença do índice Q é maior, sugerindo que as empresas possuem a maior parte de seus ativos no mercado interno, e se beneficiam da valorização da moeda local.

Como em Rossi (2008), inicialmente a seguinte equação é estimada:

$$
Q_{\text {tobin'it }}=\alpha_{i}+\delta_{t}+\beta \text {. } \text { Derivativos }_{i t}+\gamma \cdot \mathrm{X}_{i t}+\varepsilon_{i t}
$$

Onde $Q_{\text {tobin'it }}$ representa o valor Q de Tobin de cada firma i no período t, $\delta_{t}$ representa as dummies temporais, $\mathrm{X}_{i t}$ é o conjunto de variáveis de controle mencionadas anteriormente, $\beta$ o coeficiente de interesse, pois ele indica o impacto do uso de derivativos cambiais no valor da firma e $\varepsilon$ é o termo de erro.

Inicialmente, a equação (4) foi estimada em pooled OLS para todas as empresas da amostra. A variável utilizada para testar a hipótese que firmas usuárias de derivativos cambiais têm maior valor de 
mercado é a dummy uso de derivativos, que se iguala a 1, se a empresa usou derivativo de moeda em determinado ano e a 0 , caso contrário. Não foram considerados os valores praticados pelas empresas. Essa metodologia visa eliminar o efeito do tamanho das operações praticadas. Assim, excluiu-se o efeito de que empresas maiores utilizam mais derivativos, pois têm maior acesso aos mercados financeiros. Com as dummies, colocaram-se todas as empresas nas mesmas condições e conseguiu-se analisar o impacto das operações de derivativos cambiais no valor de mercado da firma.

Seguindo Allayannis e Weston (2001), para controlar as características não-observáveis das empresas que podem afetar seus valores, foi estimado um modelo de efeito fixo ${ }^{(3)}$, onde, para cada empresa, foi atribuído um único intercepto (ver regressão (2) da Tabela 3). Ainda, estimou-se o mesmo modelo por caminho aleatório (ver regressão (3) da Tabela 3).

\section{Testes de causalidade reversa}

Buscaram-se explicações alternativas para esclarecer o efeito do uso de derivativos de moedas no valor de mercado da firma. Seguindo metodologia proposta por Allayannis e Weston (2001), alto valor do índice $\mathrm{Q}$ de Tobin indica que o valor de mercado de uma empresa excede o custo de reposição de seus ativos. Se as empresas com um valor $\mathrm{Q}$ maior possuem oportunidades de investimento mais rentáveis, então essas empresas devem possuir incentivo adicional para buscarem operações de derivativos. Ou seja, se as firmas que usam derivativos de moedas possuem maior valor, isto pode simplesmente refletir o fato de que firmas com índices Qs mais altos são mais propensas a utilizarem operações de derivativos de moedas, e não o fato de que o uso destes derivativos causa aumento no valor da firma.

Para testar a possibilidade desta causalidade reversa, as firmas da amostra foram classificadas para cada ano em uma das quatro categorias: (1) empresas que não utilizaram derivativos cambiais no período corrente e no período seguinte $(\mathrm{NN})$; (2) empresas que utilizaram derivativos cambiais no período corrente, mas deixaram de utilizar no período seguinte (HN); (3) empresas que não utilizaram derivativos cambiais no período corrente e passaram a utilizar no período seguinte $(\mathrm{NH})$; e (4) empresas que utilizaram derivativos cambiais no período corrente e continuaram utilizando no período seguinte $(\mathrm{HH})$. Em seguida foram construídas variáveis dummies para as categorias (1)-(3) e foi estimada a seguinte regressão em cross-sectional:

$$
Q_{t}=\alpha+\beta_{1}(\mathrm{NN})+\beta_{2}(\mathrm{HN})+\beta_{3}(\mathrm{NH})+\gamma \mathrm{X}_{t}+\varepsilon_{t}
$$

Onde $\mathrm{X}$ representa o vetor de todas as variáveis de controle usadas nas regressões anteriores e $\varepsilon$ é o termo de erro.

Se as empresas com maior valor $\mathrm{Q}$ optam por usar derivativos cambiais, então as empresas que começam a usar derivativos no período seguinte, $\mathrm{NH}$, devem ter valor $\mathrm{Q}$ mais alto do que as empresas que permaneceram sem usar derivativos no período seguinte, NN. Portanto, espera-se que $\beta_{3}>\beta_{1}$. Ainda, se as empresas optam por não utilizar derivativos cambiais porque elas têm baixo valor $\mathrm{Q}$, então, semelhantemente, espera-se que as empresas que deixam de usar derivativos no período seguinte, têm valor $\mathrm{Q}$ mais baixo que as empresas que continuam utilizando. Logo, espera-se $\beta_{2}<0$. Finalmente, é sugerido que empresas que não usam derivativos cambiais têm valor $\mathrm{Q}$ mais baixo do que aquelas que os utilizam, ou seja, $\beta_{1}<0$.

Testaram-se as seguintes hipóteses:

H1: $\beta_{1}=0$ (o uso de derivativos cambiais não agrega valor).

H2: $\beta_{3}=\beta_{1}$ (a decisão de começar a usar derivativos cambiais não é afetada pelo tamanho do Q).

H3: $\beta_{2}=0$ (a decisão de deixar de usar derivativos cambiais não é afetada pelo tamanho do Q). 
Adicionalmente, também testou-se a restrição linear implicada pelas Hipóteses 2 e 3 , usando o teste de Wald.

\section{Estudo de evento}

Nesta subseção, continua-se seguindo Allayannis e Weston (2001) e tomou-se uma abordagem para testar a causalidade direta de que o uso de derivativos cambiais causa um aumento de valor de mercado da firma. Foi realizado um estudo de evento, onde é investigado se a decisão de começar a utilizar derivativos cambiais ou de parar de utilizá-los altera o valor da firma. A vantagem desse teste é que ele controla perfeitamente as características não-observáveis das empresas que devem afetar os testes dos níveis do índice Q.

Como na subseção anterior, classificaram-se as empresas a cada ano em quatro categorias $(\mathrm{HH}$, $\mathrm{NN}, \mathrm{HN}$, e $\mathbf{N H}$ ). Então regrediu-se a mudança de valor da firma do período $\mathbf{t}$ para $\mathbf{t}+\mathbf{1}$ nas quatro variáveis dummies citadas acima. Adicionalmente, os outros fatores que podem alterar o valor da firma são controlados pela adição da mudança das séries-temporais nas variáveis de controle usadas nos testes multivariados do nível do índice Q. O modelo de regressão estimado é:

$$
\Delta Q_{\text {tobin'it }}=\alpha_{i}+\beta_{1}(\mathrm{HH})+\beta_{2}(\mathrm{NN})+\beta_{3}(\mathrm{NH})+\beta_{4}(\mathrm{HN})+\gamma \cdot \Delta \mathrm{X}_{i t}+\delta_{t}+\varepsilon_{i t}
$$

Onde $\Delta Q_{\text {tobin' it }}$ é a variação do valor $\mathrm{Q}$ de Tobin de cada firma i no período $\mathrm{t}, \Delta \mathrm{X}_{i t}$ é o vetor de variação das variáveis de controle, $\delta_{t}$ representa as dummies temporais, e $\varepsilon$ é o termo de erro de cada firma i no período t.

Testaram-se então as seguintes hipóteses para as empresas da amostra que possuem vendas externas e também para aquelas que não possuem:

Se $\beta_{3}>\beta_{2}$, o início de uma política de uso de derivativos de moeda aumenta o valor de mercado da firma. Se $\beta_{4}<\beta_{1}$, o encerramento da política de utilização de derivativos de moeda tem impacto negativo no valor de mercado da firma, se comparado à firma que mantém sua política de usar derivativos.

Os resultados das regressões em pooled $O L S$, em modelo de efeito fixo, em modelo de efeito aleatório estão esboçados na tabela 4.

Apenas para facilitar a visualização, recordamos os diferentes métodos utilizados para calcular o índice Q de Tobin:

$$
\begin{aligned}
Q 1 & =\frac{A T-V C E+V M E}{A T} \\
Q 2 & =\frac{V M A+V C P C-V C A C+V C E+V C D L P}{A T} \\
Q 3 & =\frac{V M A+V C D}{A T}
\end{aligned}
$$


Tabela 4

Uso de Derivativos Cambiais, Variáveis de Controle e o Valor de Mercado das Empresas.

\begin{tabular}{|c|c|c|c|}
\hline Painel A - Variável dependente: Q1 & $\begin{array}{l}\text { Pooled OLS } \\
\text { (1) }\end{array}$ & $\begin{array}{l}\text { Efeito Fixo } \\
\text { (2) }\end{array}$ & $\begin{array}{c}\text { Efeito Aleatório } \\
\text { (3) }\end{array}$ \\
\hline \multirow[t]{2}{*}{ Uso de Derivativos Cambiais } & 0.118 & -0.171 & -0.088 \\
\hline & 1.346 & -1.581 & -0.887 \\
\hline \multirow[t]{2}{*}{ Diversificação Geográfica } & 0.513 & -0.528 & -0.433 \\
\hline & $1.734 * * *$ & -1.170 & -1.252 \\
\hline \multirow[t]{2}{*}{ Tamanho } & 0.000 & 0.000 & 0.000 \\
\hline & 0.053 & $2.242^{* *}$ & $1.710 * * *$ \\
\hline \multirow[t]{2}{*}{ Lucratividade } & 0.669 & 0.920 & 0.866 \\
\hline & $5.082^{*}$ & $4.833^{*}$ & $5.284^{*}$ \\
\hline \multirow[t]{2}{*}{ Alavancagem } & 0.002 & 0.023 & 0.020 \\
\hline & 0.117 & $2.085^{* *}$ & $5.284 *$ \\
\hline \multirow[t]{2}{*}{ Oportunidade de Investimentos } & 0.000 & 0.000 & 0.000 \\
\hline & 0.970 & 1.455 & 1.366 \\
\hline \multirow[t]{2}{*}{ Acesso aos Mercados Financeiros } & -0.034 & 0.265 & 0.232 \\
\hline & -0.370 & $3.382 *$ & $2.986^{*}$ \\
\hline \multirow[t]{2}{*}{ Exportadora ou Importadora } & -0.216 & 0.266 & 0.207 \\
\hline & -1.306 & $1.733 * * *$ & 1.417 \\
\hline \multirow[t]{2}{*}{ Liquidez } & 0.012 & 0.088 & 0.071 \\
\hline & 0.204 & 1.601 & 1.338 \\
\hline \multirow[t]{2}{*}{ Vendas Externas } & -0.083 & 0.543 & 0.232 \\
\hline & -0.836 & $2.734 *$ & $1.665 * * *$ \\
\hline Cross-sections & 47 & 47 & 47 \\
\hline $\mathrm{N}$ & 422 & 422 & 422 \\
\hline R2 & 0.098 & 0.633 & 0.622 \\
\hline R2 Ajustado & 0.076 & 0.577 & 0.613 \\
\hline Estatística F & 0.000 & 0.000 & \\
\hline \multicolumn{4}{|l|}{ Painel B - Variável dependente: Q2 } \\
\hline \multirow[t]{2}{*}{ Uso de Derivativos Cambiais } & 0.077 & -0.219 & -0.127 \\
\hline & 0.892 & $-2.049 * *$ & -1.302 \\
\hline \multirow[t]{2}{*}{ Diversificação Geográfica } & 0.289 & -0.327 & -0.421 \\
\hline & 0.999 & -0.732 & -1.237 \\
\hline \multirow[t]{2}{*}{ Tamanho } & 0.000 & 0.000 & 0.000 \\
\hline & 0.154 & $2.357^{* * *}$ & $1.969^{* *}$ \\
\hline \multirow[t]{2}{*}{ Lucratividade } & 0.381 & 0.735 & 0.638 \\
\hline & $2.956^{*}$ & $3.899^{*}$ & $3.952^{*}$ \\
\hline
\end{tabular}




\section{Tabela 4 (continuação)}

\begin{tabular}{|c|c|c|c|}
\hline Painel B - Variável dependente: Q2 & $\begin{array}{c}\text { Pooled OLS } \\
\text { (1) }\end{array}$ & $\begin{array}{l}\text { Efeito Fixo } \\
\text { (2) }\end{array}$ & $\begin{array}{c}\text { Efeito Aleatório } \\
\text { (3) }\end{array}$ \\
\hline \multirow[t]{2}{*}{ Alavancagem } & -0.004 & 0.019 & 0.015 \\
\hline & -0.297 & $1.736 * * *$ & $3.952 *$ \\
\hline \multirow[t]{2}{*}{ Oportunidade de Investimentos } & 0.001 & 0.000 & 0.000 \\
\hline & $1.850 * * *$ & $1.866^{* * *}$ & $1.809 * * *$ \\
\hline \multirow[t]{2}{*}{ Acesso aos Mercados Financeiros } & 0.009 & 0.259 & 0.232 \\
\hline & 0.100 & $3.340 *$ & $3.010 *$ \\
\hline \multirow[t]{2}{*}{ Exportadora ou Importadora } & -0.162 & 0.205 & 0.181 \\
\hline & -1.003 & 1.352 & 1.246 \\
\hline \multirow[t]{2}{*}{ Liquidez } & -0.118 & 0.023 & -0.008 \\
\hline & $-2.077 * *$ & 0.429 & -0.144 \\
\hline \multirow[t]{2}{*}{ Vendas Externas } & -0.043 & 0.531 & 0.192 \\
\hline & -0.448 & $2.699 *$ & 1.406 \\
\hline Cross-sections & 47 & 47 & 47 \\
\hline $\mathrm{N}$ & 422 & 422 & 422 \\
\hline $\mathrm{R} 2$ & 0.043 & 0.602 & 0.587 \\
\hline R2 Ajustado & 0.020 & 0.541 & 0.577 \\
\hline Estatística F & 0.051 & 0.000 & \\
\hline \multicolumn{4}{|l|}{ Painel C - Variável dependente: Q3 } \\
\hline \multirow[t]{2}{*}{ Uso de Derivativos Cambiais } & 0.106 & -0.202 & -0.116 \\
\hline & 1.218 & $-1.897 * * *$ & -1.185 \\
\hline \multirow[t]{2}{*}{ Diversificação Geográfica } & 0.415 & -0.374 & -0.346 \\
\hline & 1.419 & -0.841 & -1.009 \\
\hline \multirow[t]{2}{*}{ Tamanho } & 0.000 & 0.000 & 0.000 \\
\hline & -0.169 & $1.998 * *$ & 1.529 \\
\hline \multirow[t]{2}{*}{ Lucratividade } & 0.466 & 0.768 & 0.694 \\
\hline & $3.580 *$ & $4.095 *$ & $4.286^{*}$ \\
\hline \multirow[t]{2}{*}{ Alavancagem } & 0.002 & 0.021 & 0.018 \\
\hline & 0.118 & $1.934 * * *$ & $4.286^{*}$ \\
\hline \multirow[t]{2}{*}{ Oportunidade de Investimentos } & 0.000 & 0.000 & 0.000 \\
\hline & 1.535 & 1.600 & 1.600 \\
\hline \multirow[t]{2}{*}{ Acesso aos Mercados Financeiros } & -0.044 & 0.262 & 0.228 \\
\hline & -0.489 & $3.393 *$ & $2.987^{*}$ \\
\hline \multirow[t]{2}{*}{ Exportadora ou Importadora } & -0.183 & 0.228 & 0.185 \\
\hline & -1.120 & 1.508 & 1.287 \\
\hline
\end{tabular}


Tabela 4 (continuação)

\begin{tabular}{l|ccc}
\hline Painel C - Variável dependente: Q3 & Pooled OLS & Efeito Fixo & Efeito Aleatório \\
& $(1)$ & $(2)$ & $(3)$ \\
\hline Liquidez & 0.045 & 0.114 & 0.099 \\
& 0.787 & $2.119^{* *}$ & $1.901^{* * *}$ \\
Vendas Externas & 0.017 & 0.514 & 0.263 \\
& 0.170 & $2.628^{*}$ & $1.905^{* * *}$ \\
\hline Cross-sections & 47 & 47 & 47 \\
N & 422 & 422 & 422 \\
R2 & 0.070 & 0.624 & 0.614 \\
R2 Ajustado & 0.048 & 0.567 & 0.605 \\
Estatística F & 0.001 & 0.000 & \\
\hline
\end{tabular}

Nota. *1\% de significância; ** 5\% de significância; *** 10\% de significância

Não há clara evidência de que todas as empresas da amostra têm alguma exposição aos movimentos da taxa de câmbio; logo, também não é claro que o uso de derivativos cambiais adiciona valor a essas empresas. Observa-se no painel A da Tabela 3 que inconsistente com a hipótese de que empresas que usam derivativos cambiais são precificadas pelos investidores com maior valor de mercado, encontraram-se resultados negativos e insignificantes para o uso de derivativos cambiais e o valor Q da firma, usando as metodologias de efeito fixo e efeito aleatório. Nas regressões em pooled $O L S$, obtiveram-se coeficientes positivos, porém estatisticamente não-significantes. Os resultados obtidos foram consistentes com Jin e Jorion (2006), que não encontrou suporte para a hipótese de que firmas que usam derivativos de moedas têm maior valor $Q$ de Tobin do que firmas que não fazem uso desses derivativos, num estudo com 119 firmas americanas do setor de óleo e gás. Porém nossos resultados foram inconsistentes com Allayannis e Weston (2001), Hagelin e Pramborg (2004) e Rossi (2008), que encontraram que a utilização de derivativos de moedas possui uma relação positiva com o valor da firma.

Para verificar a robustez desses resultados, repetimos os mesmos testes para os valores Q2 e Q3, respectivamente. Os resultados obtidos não divergem muito daqueles encontrados no painel A. Porém, nas regressões em pooled $O L S$, observaram-se coeficientes positivos e insignificantes para os valores Q2 e Q3. Já nas regressões de efeito fixo e efeito aleatório, encontraram-se resultados negativos significantes.

Interessante observar que a estimação do valor Q1, por efeito fixo, indica resultado $17,1 \%$ inferior para as empresas da amostra que utilizam derivativos de moedas. Esse número, não é estatisticamente significante, no entanto. As estimações dos valores Q2 e Q3 indicam os resultados de $-21,9 \%$ e $-20,2 \%$ respectivamente e, esses números são estatisticamente significantes.

Com relação às variáveis de controle, surpreendentemente observa-se um relacionamento nulo entre o tamanho e o valor da firma. Os resultados são inconsistentes com o encontrado por Mian (1996), no qual empresas maiores têm mais acesso ao mercado financeiro, maior ganho de escala e, portanto, maior valor. Os resultados observados divergem também daqueles encontrados por Jin e Jorion (2006), onde empresas maiores foram precificadas com prêmio de até 6\%. Já Allayannis e Weston (2001) encontraram coeficientes negativos para a variável tamanho. Interessante observar que os resultados encontrados para a variável oportunidade de investimentos é muito semelhante aos resultados da variável tamanho, o que confirma que empresas maiores, possuem mais oportunidades de investimento. 
A variável acesso aos mercados financeiros é positivamente relacionada ao valor da firma e estatisticamente significante. Isso indica que as empresas que pagam mais dividendos não têm seu valor de mercado reduzido. Resultado semelhante foi encontrado por Jin e Jorion (2006).

Os resultados confirmam que firmas mais lucrativa apresentam Qs mais altos. Esse resultado sugere que empresas mais rentáveis têm mais acesso a investimentos e maiores oportunidades de crescimento. A lucratividade nos resultados tem peso muito grande no valor da firma, representando até $92 \%$ de seu valor. A variável que mensura a alavancagem da empresa também mostrou relação positiva e relevante com o valor da firma, estando consistente com Rossi (2008) e confirmando as teorias do monitoramento exercido pela dívida ou a importância de tax shields.

Para empresas com vendas externas, os resultados confirmam uma relação positiva com o valor da firma. Essa relação pode ocorrer pelo fato de que a moeda se depreciou em relação ao dólar, beneficiando as empresas que possuem venda naquela moeda.

\section{Resultado dos testes de causalidade reversa} Tabela 5 .

Os resultados da estimação em OLS do modelo de regressão descrito acima são apresentados na

Tabela 5

Evidência em Séries Temporais. Resultados dos Testes de Causalidade Reversa

\begin{tabular}{|c|c|c|c|c|}
\hline Variável dependente: $\mathrm{Q}$ de Tobin no instante $\mathrm{t}$ & $\mathrm{N}$ & Q1 & Q2 & Q3 \\
\hline \multirow[t]{2}{*}{ Firmas que não utilizaram derivativos em ambos os períodos (NN) } & 83 & 0.285 & 0.334 & 0.313 \\
\hline & & $2.016 * *$ & $2.392 * *$ & $2.255 * *$ \\
\hline \multirow[t]{2}{*}{ Firmas que pararam de usar derivativos no período seguinte $(\mathrm{HN})$} & 5 & 0.423 & 0.422 & 0.440 \\
\hline & & $1.834 * * *$ & $1.847 * * *$ & $1.937 * * *$ \\
\hline \multirow[t]{2}{*}{ Firmas que começaram a usar derivativos no período seguinte $(\mathrm{NH})$} & 14 & 0.170 & 0.217 & 0.206 \\
\hline & & 1.629 & 0.466 & $2.153 * *$ \\
\hline Cross-sections & & 47 & 47 & 47 \\
\hline $\mathrm{N}$ & & 423 & 423 & 423 \\
\hline $\mathrm{R} 2$ & & 0.630 & 0.598 & 0.621 \\
\hline R2 Ajustado & & 0.572 & 0.535 & 0.562 \\
\hline Estatística F & & 0.000 & 0.000 & 0.000 \\
\hline \multicolumn{5}{|l|}{ Teste de Wald (p-value) } \\
\hline Hipótese 1: $\mathrm{NN}=0$ (o uso de derivativos cambiais não agrega valor) & & 0.044 & 0.017 & 0.025 \\
\hline $\begin{array}{l}\text { Hipótese } 2: \mathrm{NH}=\mathrm{NN} \text { (a decisão de começar a usar derivativos } \\
\text { cambiais não é afetada pelo tamanho do Q) }\end{array}$ & & 0.513 & 0.497 & 0.532 \\
\hline \multicolumn{5}{|l|}{ Hipótese 3: HN = 0 (a decisão de parar de usar derivativos cambiais } \\
\hline não é afetada pelo tamanho do Q) & & 0.067 & 0.065 & 0.053 \\
\hline Hipóteses 2 e 3 juntas & & 0.163 & 0.157 & 0.137 \\
\hline
\end{tabular}

Nota. * $1 \%$ de significância; $* * 5 \%$ de significância; *** $10 \%$ de significância 
Os resultados encontrados mostram que as firmas que utilizam derivativos de moedas são precificadas com maior valor do que aquelas que não se valem dos derivativos. Observa-se que, com nível de significância de 5\%, se rejeita a hipótese que o uso de derivativos cambiais não aumenta o valor Q das empresas da amostra ( $p$-value de 0.044 para o valor Q1, 0.017 para o Q2 e 0.025 para o Q3). Esses resultados se confrontam com aqueles observados nos testes em modelo de efeito fixo e modelo de efeito aleatório, esboçados na seção anterior. Semelhantemente, com nível de significância de $10 \%$, pode-se rejeitar a hipótese 3 de que a decisão de parar de usar derivativos de moedas não é afetada pelo valor $\mathrm{Q}$.

Porém não se pode rejeitar a hipótese 2 de que a decisão de começar a usar derivativos de moedas não é afetada pelo valor Q ( $p$-value de 0.513 para o valor Q1, 0.497 para o Q2 e 0.532 para o Q3). Ainda, os resultados dos testes não rejeitam a hipótese nula de não causalidade reversa, definida pelas hipóteses 2 e 3, testadas em conjunto. Com exceção da decisão de parar de usar derivativos cambiais, não se encontrou evidência de que a correlação entre o uso de derivativos cambiais e o valor de mercado da firma se origina da causalidade reversa. Esse resultado é consistente com a hipótese de que o uso de derivativos cambiais causa aumento no valor de mercado da firma.

\section{Resultado do estudo de evento}

Os resultados das regressões do modelo de estudo de evento para todas as empresas da amostra são apresentados na Tabela 6.

Tabela 6

Estudo de Evento das Mudanças da Política de Uso de Derivativos de Moedas no Valor da Firma

\begin{tabular}{|c|c|c|c|c|}
\hline Variável dependente: $\mathrm{Q}$ de Tobin no instante $\mathrm{t}$ & $\mathrm{N}$ & Q1 & Q2 & Q3 \\
\hline \multirow{2}{*}{ Firmas que usaram derivativos em ambos os períodos $(\mathrm{HH})$} & 330 & 1.029 & 0.880 & 0.794 \\
\hline & & $6.887^{*}$ & $6.053^{*}$ & $5.335^{*}$ \\
\hline \multirow[t]{2}{*}{ Firmas que pararam de usar derivativos no período seguinte (HN) } & 5 & 1.143 & 1.075 & 0.927 \\
\hline & & $3.609 *$ & $3.485^{*}$ & $2.937^{*}$ \\
\hline Diferença $(\mathrm{HH}$ - HN) & & -0.114 & -0.194 & -0.133 \\
\hline Prêmio & & $-11.4 \%$ & $-19.4 \%$ & $-13.3 \%$ \\
\hline Teste de Wald (p-value): $\mathrm{HH}=\mathrm{HN}$ & & 0.703 & 0.507 & 0.657 \\
\hline \multirow[t]{2}{*}{ Firmas que começaram a usar derivativos no período seguinte $(\mathrm{NH})$} & 14 & 1.042 & 0.932 & 0.800 \\
\hline & & $4.923^{*}$ & $4.522 *$ & $3.797^{*}$ \\
\hline \multirow[t]{2}{*}{ Firmas que não utilizaram derivativos em ambos os períodos (NN) } & 83 & 0.961 & 0.848 & 0.723 \\
\hline & & $6.468 *$ & $5.864 *$ & $4.888^{*}$ \\
\hline Diferença (NH - NN) & & 0.081 & 0.084 & 0.077 \\
\hline Prêmio & & $8.1 \%$ & $8.4 \%$ & $7.7 \%$ \\
\hline Teste de Wald (p-value): $\mathrm{NH}=\mathrm{NN}$ & & 0.671 & 0.652 & 0.685 \\
\hline Teste de Wald (p-value): $\mathrm{HH}=\mathrm{HN}$ e $\mathrm{NH}=\mathrm{NN}$ & & 0.849 & 0.724 & 0.834 \\
\hline
\end{tabular}

Nota. * $1 \%$ de significância; ** 5\% de significância; *** $10 \%$ de significância

Observa-se que para os 3 valores do índice $Q$ de Tobin, os resultados são bastante semelhantes e em todos os testes, os coeficientes encontrados são estatisticamente significantes para um intervalo de confiança de $1 \%$. Foi verificado que, surpreendentemente, as empresas que usaram derivativos cambiais no período corrente e deixaram de utilizar no período seguinte, tiveram seu valor $\mathrm{Q}$ 
fortemente superior ao valor daquelas que continuaram a utilizar tais derivativos. A magnitude desse aumento é da ordem de 11,4\% para o valor Q1, 19,4\% para o valor Q2 e 13,3\% para o valor Q3. Esses números divergem bastante dos resultados encontrados por Allayannis e Weston (2001), que obtiveram resultados positivos de $2,1 \%$ para as empresas que mantiveram a política de usar derivativos de moedas.

Porém, consistente com Allayannis e Weston (2001), observou-se que as empresas que não utilizavam derivativos de moedas no período corrente, mas passaram a utilizá-los no período seguinte, tiveram seus valores Qs superiores aos valores das empresas que não utilizavam instrumentos derivativos no período corrente e mantiveram a mesma política no período seguinte. A magnitude do prêmio é da ordem de 8,1\% para o valor Q1, 8,4\% para o valor Q2 e 7,7\% para o valor Q3. Por fim, testaram-se as hipóteses $\beta_{3}>\beta_{2}$ e $\beta_{4}<\beta_{1}$ em conjunto, usando o mesmo teste de Wald. Para todos os valores $\mathrm{Q}$, não se rejeita a hipótese de que não há relação entre a política de usar derivativos cambiais e o valor de mercado da firma. Esse resultado é consistente com aqueles encontrados nas seções anteriores deste trabalho.

\section{Conclusão}

Este trabalho analisou o impacto do uso de derivativos de moedas no valor de mercado da firma em amostra das 48 empresas não-financeiras mais líquidas, listadas na Bovespa, no período de 1999 a 2007. Para tanto controlaram-se outras variáveis que a teoria sugere que devam afetar o valor da firma, entre elas: tamanho, acesso aos mercados financeiros, alavancagem, lucratividade, oportunidade de investimentos, liquidez, diversificação geográfica, efeitos do tempo, vendas externas e se a firma é exportadora ou importadora.

Num exercício de robustez, foram utilizadas 3 medidas do índice $Q$ de Tobin como aproximação do valor da firma, e fez-se regredir o modelo em diferentes metodologias econométricas, com base em Allayannis e Weston (2001): pooled OLS, modelo de efeito fixo e modelo de efeito aleatório. Porém a hipótese de que as firmas que usam derivativos de moedas têm valor de mercado maior do que as firmas que não os usam foi rejeitada nas 3 metodologias, coincidindo com os resultados encontrados por Jin e Jorion (2006), num estudo sobre a atividade de hedge com 119 empresas americanas do setor de óleo e gás.

Adicionalmente, complementando um estudo publicado no Brasil por Rossi (2008), foram realizados testes de causalidade reversa e estudos de evento, para examinar como a política de usar derivativos de moedas influencia o valor de mercado da firma. Encontraram-se evidências de que as empresas que iniciam o uso desses derivativos experimentam um aumento de seu valor de mercado. Porém aquelas empresas que deixam de usar esses instrumentos, em determinado momento, também têm seu valor de mercado aumentado. Logo, não se encontrou clara evidência de que o uso de derivativos cambiais está associado ao incremento do valor de mercado da firma.

Por fim, as análises realizadas neste estudo ainda podem ser melhoradas nas futuras pesquisas. Nem todas variáveis de controle, discutidas na segunda seção, foram incorporadas no modelo, devido à falta de disponibilidade de dados. O tamanho das operações de derivativos de cada firma em relação a seu tamanho, por exemplo, é um dado que poderia ajudar a aprofundar a análise, mas poucas empresas divulgam essas informações em detalhe. Além disso, outras variáveis de controle que sinaliza o esforço das firmas em utilizar derivativos de moedas para minimizar a flutuação de seu fluxo de caixa também poderiam ser usadas.

\section{Artigo recebido em 29.09.2009. Aprovado em 20.09.2010.}




\title{
Agradecimentos
}

Os autores agradecem as importantes contribuições e comentários dos dois pareceristas e da consultoria editorial da RAC, estendendo os agradecimentos aos participantes dos seminários de pesquisa da FGV-EESP e EAESP e do Encontro de Finanças 2009.

\section{Notas}

\author{
${ }^{1}$ Para maiores detalhes ver Famá e Barros (2000). \\ ${ }^{2}$ Para mais detalhes ver Allayannis e Weston (2001). \\ ${ }^{3}$ Para mais detalhes ver Hausman, J. A., \& Taylor W. E. (1981). Panel data and unobservable individual effects. \\ Econometrica, 49(6), 1377-1398.
}

\section{Referências}

Allayannis, G., Lel, U., \& Miller, D. (2007). Corporate governance and the hedging premium around the world [Working paper]. Darden Business School, Virginia, USA.

Allayannis, G., \& Weston, J. P. (2001). The use of foreign currency derivatives and firm value. The Review of Financial Studies, 14(1), 243-276. doi: 10.1093/rfs/14.1.243

Bodnar, G., Tang, C., \& Weintrop, E. J. (1999). Both sides of corporate diversification: the value impacts of geographical and industrial diversification [Working paper]. Wharton Business School, Pennsylvania, USA.

Brando, J. A. (2008, June 20). Por que as firmas fazem hedge? Coluna InfoMoney. InfoMoney. Recuperado http://web.infomoney.com.br/templates/news/view.asp?codigo=1185453\&path=/investimentos/ noticias/colunistas/

Brito, D. R., \& Lima, R. M. (2004). A escolha da estrutura de capital sob fraca garantia legal: o caso do Brasil [Working Paper]. Ibmec São Paulo, São Paulo, SP, Brasil.

Chung, K. H., \& Pruitt, S. W. (1994). A simple approximation of Tobin's Q. Financial Management, 23(3), 70-74.

Famá, R., \& Barros, L. A. B. C. de (2000). Q de Tobin e seu uso em finanças: aspectos metodológicos e conceituais. Caderno de Pesquisas em Administração, 7(4), 27-43.

Hagelin, N., \& Pramborg, B. (2004). Hedging foreign exchange exposure: risk reduction form transaction and translation hedging. Journal of International Financial Management and Accounting, 15(1), 1-20. doi: 10.1111/j.1467-646X.2004.00099.x

Jensen, M. C. (1986). Agency cost of free cash flow, corporate finance and takeovers. American economic review, 76(2), 323-329. doi:10.2139/ssrn.99580

Jin, Y., \& Jorion, P. (2006). Firm value and hedging: evidence from U.S. oil and gas procucers. The Journal of Finance, 61(2), 893-919.

Lang, L. H. P., \& Stulz, R. M. (1994). Tobins's q, corporate diversification, and firm performance. The Journal of Political Economy, 102(6), 1248-1280. 
Lewellen, W. G., \& Badrinath, S. G. (1997). On the measurement of Tobin's q. Journal of Financial Economics, 44(1), 77-123.

Mian, S. (1996). Evidence on corporate hedging policy. Journal of Financial and Quantitative Analysis, 31(3), 419-439.

Mork, Y., \& Yeung, B. (1991). Why investors value multinacionality. Journal of Business, 64(2), 165187. doi: $10.2307 / 2353061$

Myers, S. C. (1977). Determinants of corporate borrowing. Journal of Financial Economics, 5(2), $147-175$.

Perfect, S., \& Wiles, K. (1994). Alternative constructions of Tobin's Q: an empirical comparison. Journal of Empirical Finance, 1(3-4), 313-341.

Pramborg, B. (2004). Derivatives hedging, geographical diversification, and firm market value. Journal of Multinational Financial Management, 14(2), 117-133.

Reinhart, W. J. (1977). The theoretical development and empirical investigation of a relative valuation concept (Dissertation). University of North Carolina, Chapel Hill.

Rossi, J. L., Jr. (2008). A utilização de derivativos agrega valor à firma? Um estudo do caso brasileiro. Revista de Administração de Empresas, 48(4), 94-107. doi: 10.1590/S003475902008000400009

Servaes, H. (1996). The value of diversification during the conglomerate merger wave. Journal of Finance, 51(4), 1201-1225.

Shin, H., \& Stulz, R. (2000). Firm value, risk and growth opportunities [Working paper]. National Bureau of Economic Research, Cambridge, Massachusests, USA.

Tavares, G., \& Sheng, H. H. (2007). Estimando a exposição cambial de empresas da Bovespa. Anais do Encontro Brasileiro de Finanças, São Paulo, SP, Brasil, 7.

Tobin, J. A. (1969). A general equilibrium approach to monetary theory. Journal of Money, Credit and Banking, 1(1), 15-29.

Tobin, J. A., \& Brainard, W. (1968). Pitfalls in financial model-building. The American Economic Review, 58(2), 99-122.

Yermack, D. (1996). Higher market valuation of companies with a small board of directors. Journal of Financial Economics, 40(2), 185-211. doi:10.1016/0304-405X(95)00844-5 